\title{
Influence of baking conditions on the quality attributes of sponge cake
}

\author{
M Micaela Ureta ${ }^{1}$, Daniela F Olivera ${ }^{1}$ and Viviana O Salvadori ${ }^{1,2}$
}

\begin{abstract}
Sponge cake is a sweet bakery product characterized by its aerated and soft crumb and by its thin-coloured crust. The aim of this work is to analyse the influence of baking conditions (natural or forced convection, steam injection, oven temperature from $140^{\circ} \mathrm{C}$ to $180^{\circ} \mathrm{C}$ ) on sponge cake quality. Both crust and crumb regions were characterized by means of colour development, water content, crust/crumb relation, crust thickness and crumb structure (in terms of porosity, crumb density and texture). Colour measurements allowed obtaining an accurate model for browning kinetics. Crumb water content remains almost constant, while considerable dehydration occurs in the crust. In general, no significant differences due to baking conditions were found in the instrumental quality analysis.
\end{abstract}

\section{Keywords}

Sponge cake, baking conditions, quality

Date received: 6 May 2016; accepted: 1 August 2016

\section{INTRODUCTION}

Sponge cake is a type of sweet bakery product characterized by its aerated and soft crumb and by its thin coloured crust. This product is produced all over the world and is decorated with different fillings, colours and flavours to create different kinds of cakes. In general, it is associated with celebrations and meetings, and it must fit to high-quality standards required by the consumers.

From a technological point of view, baking is a crucial stage for sponge cake production. In this sense, during baking, a complex mix (batter) containing many ingredients (such as wheat flour, sugar, egg, fat, leavening agents, salt, milk solids and water) changes from fluid state to a porous structure. This transformation is the result of different reactions and interactions which occur as the product's temperature increases.

Food Science and Technology International 23(2) 156-165 (C) The Author(s) 2016 Reprints and permissions: sagepub.co.uk/journalsPermissions.nav DOI: $10.1177 / 1082013216666618$ journals.sagepub.com/home/fst ๑SAGE
The rate of heat transfer, the amount of supplied heat, the humidity level within the baking chamber and the duration of the baking process influence the quality of the final product (Sani et al., 2014).

During the last decades, several authors have studied and linked the influence of baking conditions on product quality for different bakery products. Baik et al. (2000) evaluated some important quality parameters, such as texture, colour, density and viscosity of the cake batter during baking in two different multi-zone industrial scale ovens: gas-fired band oven and electricpowered mould oven, both operating in a similar range of temperature to the one selected for the present work. Lostie et al. (2002a) studied the texture evolution of sponge cake by means of image analysis baked under

${ }^{1}$ Centro de Investigación y Desarrollo en Criotecnología de Alimentos (CIDCA), CCT-CONICET La Plata and Facultad de Ciencias Exactas, UNLP, La Plata, Argentina

${ }^{2}$ DIQ, Facultad de Ingeniería, UNLP, La Plata, Argentina

\section{Corresponding author:}

M Micaela Ureta, Centro de Investigación y Desarrollo en Criotecnología de Alimentos (CIDCA), CCT-CONICET La Plata and Facultad de Ciencias Exactas, UNLP, 47 y 116, La Plata 1900, Argentina.

Email: micaelaureta@gmail.com 
natural convection (NC) at $200^{\circ} \mathrm{C}$ and $240{ }^{\circ} \mathrm{C}$. Sumnu et al. (2005) and Turabi et al. (2008) focused on the optimization of rice cake baking using a combination of microwave and infrared technology, considering different quality parameters as weight loss, specific volume, firmness and colour. Fehaili et al. (2010) monitored the thermal reactions during baking of sponge cake (convective oven, $140{ }^{\circ} \mathrm{C}-200^{\circ} \mathrm{C}$ ) identifying three phases according to the relative importance of conductive and evaporative internal heat transfer regimes and to macroscopic changes (crust formation) in the cake structure. Vignali and Volpi (2013) evaluated different features (water activity, humidity, $\mathrm{pH}$ and sensorial judge) of a final baked product, Panettone, using the Design of Experiments technique. Chhanwal et al. (2015) studied the use of infrared radiation to achieve a more efficient baking process in terms of bread quality attributes: moisture content, volume, crumb firmness, colour and sensory analysis. The results showed that breads baked with infrared had higher moisture content, higher volume, lower crumb firmness and similar overall quality score compared with conventional baking process. Shahapuzi et al. (2015) analysed the effect of the airflow on the oven temperature profile, the internal cake temperature and the cake quality. The authors found that the presence of airflow induced a faster heating rate, a higher volume expansion rate and a more porous crumb texture.

Particularly, this work was done in the framework of a research focused on the study of the baking process of sweet baked products. Regarding sponge cake, recently, Ureta et al. (2016) published an experimental characterization of the process (three convection modes, three oven temperatures) accompanied with a mathematical model simulating the heat transfer dynamics. In this context, and following the line of research, the aim of the present work is to complete the analysis, evaluating the influence of the operative conditions on sponge cake quality.

Therefore, both crust and crumb regions were characterized in terms of colour development, water content, crust/crumb relation, crust thickness and crumb structure.

\section{MATERIALS AND METHODS}

\section{Batter preparation}

Batter cake recipe was formulated with $270 \mathrm{~g}$ whole fresh eggs mixed for $2 \mathrm{~min}$ at $240 \mathrm{r} / \mathrm{min}$ in a multifunction food processor (Rowenta Universo 700, France) and then $360 \mathrm{~g}$ dry premix (containing wheat flour, sugar, wheat starch, leavening agents, salt, flavours), Tegral Satin Cream Cake Premix (Puratos, Argentine) were added and mixed for another $2 \mathrm{~min}$. The final batter composition was $45.4 \%$ carbohydrates, $9.7 \%$ proteins, $7.2 \%$ fat, $1.7 \%$ ashes and $36.0 \%$ water. After mixing, $500 \mathrm{~g}$ batter was dosed in an aluminium mould (18 cm diameter, $7 \mathrm{~cm}$ height).

\section{Sponge cake baking}

Baking tests were performed with NC (domestic oven Ariston FM87-FC, Italy), and with forced convection and steam-assisted forced convection modes (FC and SFC, respectively - semi-industrial convection oven Multiequip HCE-3/300, Argentine). Both ovens have similar useful volume ( $53 \mathrm{~L}$ and $58.8 \mathrm{~L}$, respectively). The first one operates with upper and lower resistances, and the second one has a fan installed on the back wall, which propelled the air at $2.8 \mathrm{~m} / \mathrm{s}$ (fixed air velocity, measured with a multifunction measuring instrument, TESTO 435, equipped with a vane probe TESTO, Germany). The latter has also a connection pipe to provide steam to the cooking chamber. Each test under SFC consumed ca. $600 \mathrm{~mL}$ water to generate steam, which was added in five equally spaced periods along the SFC baking tests.

For each convection mode, three series of experimental runs were performed, setting the nominal oven temperature at $140^{\circ} \mathrm{C}, 160^{\circ} \mathrm{C}$ and $180^{\circ} \mathrm{C}$, respectively (nine total baking conditions). The oven was preheated for several minutes until it reached the pre-set temperature of each condition.

\section{Temperature measurement}

T-type thermocouples (Omega, USA) connected to a data logger (Keithley DASTC, USA) were used to record oven and sponge cake temperature during the baking tests. Oven temperature was recorded by placing two thermocouples in the centre of the oven chamber, near the sample. Two replicates were performed for each baking condition.

Cake temperature profiles were obtained with three thermocouples attached to the mould before filling it with the batter (without interfering with cake evolution). The placement of the thermocouples was chosen according to the previous reported results (Ureta et al., 2016), in which it was highlighted that the last region to achieve a complete crumb development and an adequate degree of baking was the one near the axial axis (r0) and just below the superficial top crust.

Therefore, two of the thermocouples were positioned in the axial axis of the sample $(\mathrm{r}=0)$ at $0.075 \mathrm{~m}(\mathrm{~T} 1)$ and $0.055 \mathrm{~m}$ (T2) from the bottom mould. At the beginning of the baking process, both of them were outside the sample, and they were covered while expansion occurred. The third one (T3) was positioned near the mould wall $(\mathrm{r}=0.075 \mathrm{~m})$, at $0.02 \mathrm{~m}$ from the mould 
bottom. This thermocouple was inside the sample during the whole experiment.

\section{Crust and crumb analysis}

As it was mentioned, during baking, several physical and chemical reactions are produced. Consequently, the initial batter, fluid, is transformed into a solid, sponge porous structure. In the final baked product, two zones are easily distinguished: the crumb and the crust.

To analyse the influence of the baking conditions on the characteristics of both zones, different instrumental measurements were performed, two of them (crust colour and water content) along the whole baking process, the other ones only in the final baked cake.

Kinetic of crust colour development. Along baking, the surface colour changes, from light cream yellow of the initial batter to gold brown, typical of sweet baked goods. This evolution was quantified using the CIELab parameters (L-lightness, a-redness, b-yellowness), measured with a MINOLTA CR-300 tristimulus colorimeter (Osaka, Japan). In order to observe this colour change, partial baking tests were designed (Ureta et al., 2014a) measuring the initial batter colour, early crust formation, four intermediate values, and finally, a burned product. Reported values for each time and baking condition correspond to the average of eight measurements.

The crust browning evolution is represented by a browning index, BI (equation (1))

$$
\mathrm{BI}=\frac{[100(x-0.31)]}{0.172}
$$

where

$$
x=\frac{(a+1.75 L)}{(5.645 L+a-3.012 b)}
$$

This index has been proved to represent satisfactorily the browning of sweet baked products (Sakin-Yilmazer et al., 2013; Ureta et al., 2014a).

Water content. Central crumb and upper crust water content was measured along baking, for $\mathrm{NC1}$ condition, performing partial baking tests. For the other eight baking conditions, only final product values were determined. The crust was carefully separated using a scalpel and the water content of each section ( $\mathrm{WC}_{\text {crust }}$ and $\mathrm{WC}_{\text {crumb }}$, respectively, \%, wet basis) was determined by drying $3-5 \mathrm{~g}$ of sample in a stove at $105^{\circ} \mathrm{C}$, until constant weight was achieved. The results are the average of four replicates.

Crust/crumb ratio. Crust/crumb ratio was calculated according to Le-Bail et al. (2011). The samples were removed from the oven and cooled for a few minutes; the crust was separated from the crumb using a scalpel, considering the crust as the dried and brown surface located at the upper zone of the muffin. The crust-tocrumb ratio was expressed as the mass ratio on wet basis. Four replicates were made for each tested condition.

Crust thickness. To quantify crust thickness in this work, a non-destructive method of image analysis was implemented by using low-intensity ultrasound, best known as echography (Kossoff, 2000). In general terms, the technique consists in the emission of highfrequency sound waves, released by a transducer through the studied object. The transducer picks up the echoes of different amplitude generated by the rebound of the sound wave in the diverse issues and structures which comprise the object. The equipment software processes the signals giving as a result images of the examined issues differentiating the shape and the size of each structure, as well as their components.

In this study, portable ultrasound equipment (MindrayDP-2200, China) with a 17-cm lineal transducer adjusted at $3.5 \mathrm{MHz}$ was used. Measurements were done by placing the transducer on the top surface of the cake baked on the same day ( $5 \mathrm{~h}$ after the end of the process). Crust thickness was calculated with the equipment's software. Reported results are an average of four measurements (using two sponge cakes for each baking condition).

Crumb structure. Crumb structure in this work is represented by three physical properties, i.e. porosity, density and texture. Porosity $\left(\phi\right.$, cell $\left.\mathrm{cm}^{-2}\right)$ is defined as the ratio between the number of pores and the area. It was measured by image analysis, using a technique previously developed for muffins (Ureta et al., 2014a). Crumb density $\left(\rho_{c}, \mathrm{~kg} \mathrm{~m}^{-3}\right)$ was determined from crumb cylinders cut from the central zone of the sponge cake, using a cork borer. The crumb cylinder was weighed, and its volume was calculated from its height and diameter, measured with a calliper.

To identify the mechanical properties of the sponge cake, a compression test was performed using a TA.XT2i Texture Analyzer (Stable Micro Systems, UK), equipped with a 75-mm-diameter aluminium probe $(\mathrm{P} / 75)$. Cylinders of crumb, $2.65 \mathrm{~cm}$ diameter 
and $1 \mathrm{~cm}$ height, selected from the centre of the cake, were measured. The test speed was $1 \mathrm{~mm} / \mathrm{s}$, and the strain was $25 \%$ of the total height. The maximum force was a firmness indicator $(\mathrm{F}, \mathrm{N})$ of the sponge cake's crumb.

\section{Statistical analysis}

The data were subjected to analysis of variance. Comparison of means was conducted using Fisher's least significant difference test, with $5 \%$ significance level.

\section{RESULTS AND DISCUSSION \\ Temperature profiles and baking time}

Figure 1 shows the temperature profiles. First of all, oven temperature presents a periodic behaviour (due to the oven ON-OFF control system), with an average effective temperature ( $T_{\text {eff }}$, dashed lines) which differs from the nominal temperature. Hence, each baking condition will be identified with the nomenclature presented in Table 1.
Secondly, referring to product temperature profile, $\mathrm{T} 1$ and $\mathrm{T} 2$ initially present a periodic profile with values over $100^{\circ} \mathrm{C}$, because in spite of being close to

Table 1. Effective oven temperature $\left(\mathrm{T}_{\text {eff }},{ }^{\circ} \mathrm{C}\right)$ and baking time $\left(t_{\min }, \min \right)$, with their respective standard error, for the different operative conditions tested in this study: natural convection (NC), forced convection (FC) and steamassisted forced convection (SFC)

\begin{tabular}{clll}
\hline Nominal temperature & 140 & 160 & 180 \\
\hline Natural convection & $\mathrm{NC} 1$ & $\mathrm{NC} 2$ & $\mathrm{NC3}$ \\
$\mathrm{T}_{\text {eff }}\left({ }^{\circ} \mathrm{C}\right)$ & $145.4 \pm 4.5$ & $161.4 \pm 4.7$ & $185.8 \pm 4.1$ \\
$\mathrm{t}_{\text {min }}(\mathrm{min})$ & $51.4 \pm 0.3$ & $42.6 \pm 1.2$ & $32.3 \pm 1.6$ \\
Forced convection & $\mathrm{FC} 1$ & $\mathrm{FC} 2$ & $\mathrm{FC} 3$ \\
$\mathrm{~T}_{\text {eff }}\left({ }^{\circ} \mathrm{C}\right)$ & $150.2 \pm 6.9$ & $175.6 \pm 4.9$ & $194.0 \pm 5.5$ \\
$\mathrm{t}_{\text {min }}(\mathrm{min})$ & $40.3 \pm 0.6$ & $41.8 \pm 0.8$ & $29.7 \pm 1.0$ \\
Steam-assisted & $\mathrm{SFC} 1$ & $\mathrm{SFC} 2$ & $\mathrm{SFC} 3$ \\
forced convection & & & \\
$\mathrm{T}_{\text {eff }}\left({ }^{\circ} \mathrm{C}\right)$ & $151.2 \pm 6.3$ & $166.2 \pm 6.1$ & $183.5 \pm 6.7$ \\
$\mathrm{t}_{\text {min }}(\mathrm{min})$ & $40.0 \pm 0.5$ & $31.8 \pm 1.2$ & $28.5 \pm 0.7$ \\
\hline & & &
\end{tabular}

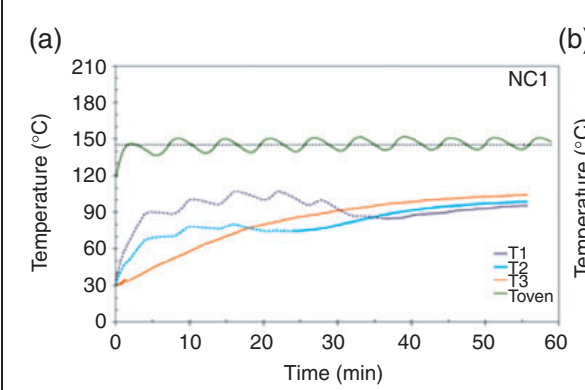

(b)

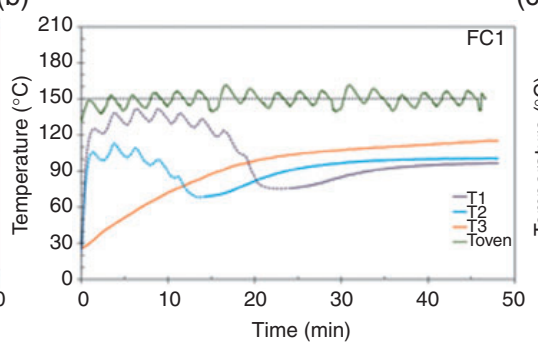

(c)
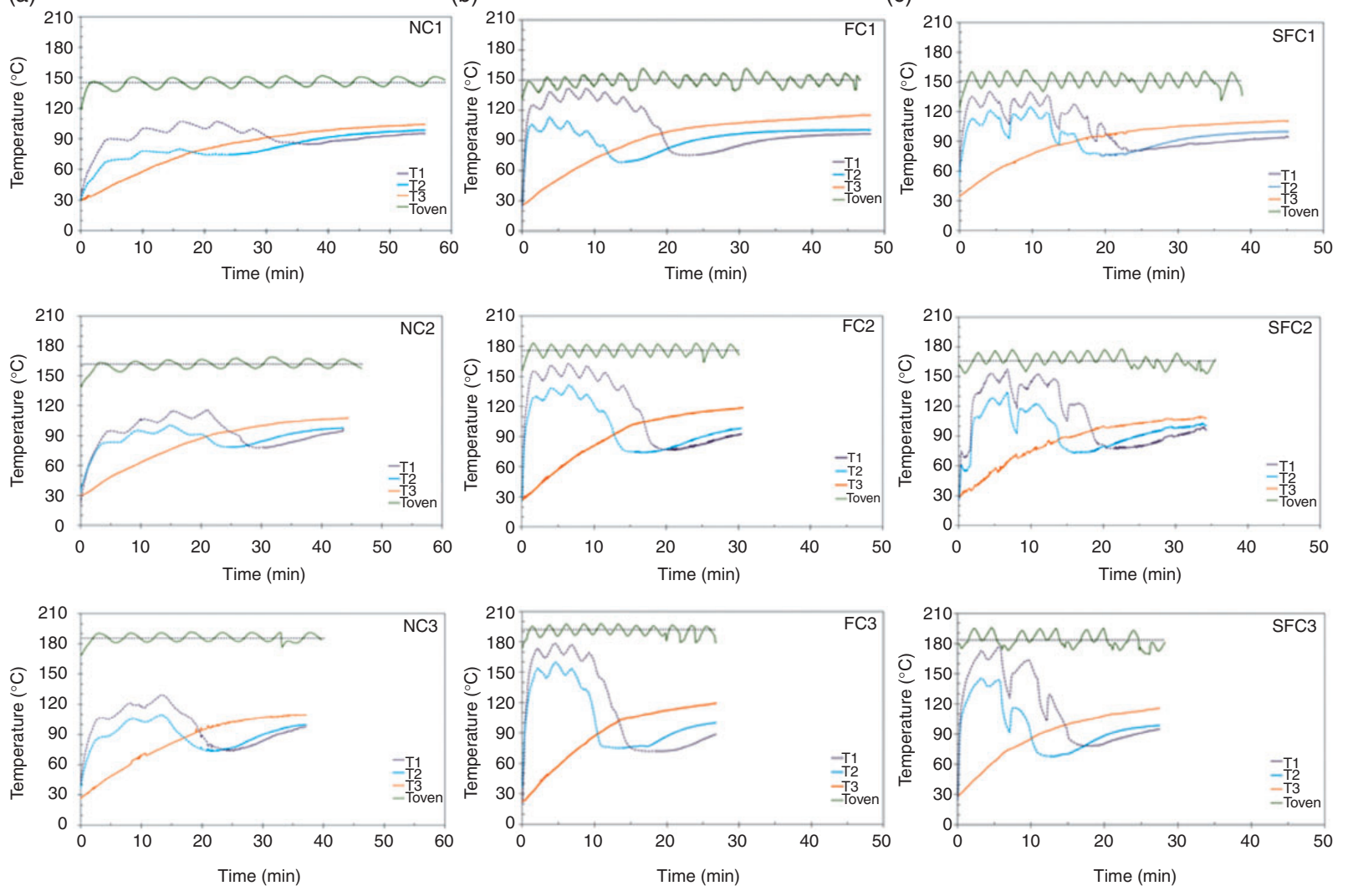

Figure 1. Oven and sponge cake temperature profiles: (a) natural convection NC, (b) forced convection FC and (c) steam-assisted forced convection SFC modes. 
the cake surface, they measure air temperature. As sponge cake baking progresses and thus, cake volume expansion evolves, T1 and T2 start decreasing their temperature values until they are immersed in the product. By this time, recorded temperature is in the range of $70^{\circ} \mathrm{C}-80^{\circ} \mathrm{C}$, and then it increases up to a stabilization value around $95^{\circ} \mathrm{C}$. This value is considered a reference to ensure a complete starch gelatinization and protein denaturation, meaning a complete crumb setting (Ahrné et al., 2007; Ureta et al., 2016). Based on this, the minimal baking time $\left(\mathrm{t}_{\min }\right)$ is defined as the instant when $\mathrm{T} 1$ reaches $95^{\circ} \mathrm{C}$; these process times are also detailed in Table 1. The first finding from these results suggests that no matter the convection mode, $t_{\min }$ decreases with an increment of the oven temperature. Furthermore, an exponential dependence between these two variables was found, where two groups of data could be distinguished: $\mathrm{NC}$ and FC with and without steam injection (Ureta et al., 2016).
On the contrary, as T3 is close to the mould wall and is inside the sample from the beginning of baking, it shows an increasing temperature during all the process, and finally stabilizes near $105^{\circ} \mathrm{C}$.

Similar trends were observed for the nine baking conditions studied in this work. It is worth mentioning that all the determinations referring to cake quality in this work (water content, crust/crumb ratio, crust thickness and crumb structure characteristics) correspond to a product baked at $t_{\text {min }}$.

\section{Crust and crumb analysis}

Kinetic of crust colour development. Figure 2(a) shows the evolution of the BI vs. baking time, for the different baking conditions tested in this work. As it was detailed, BI adequately represents the colour of sponge cake surface; this fact is visualized in Figure 2(b). The sigmoid trend of BI vs. time is similar to that reported for other sweet baked products (Ureta

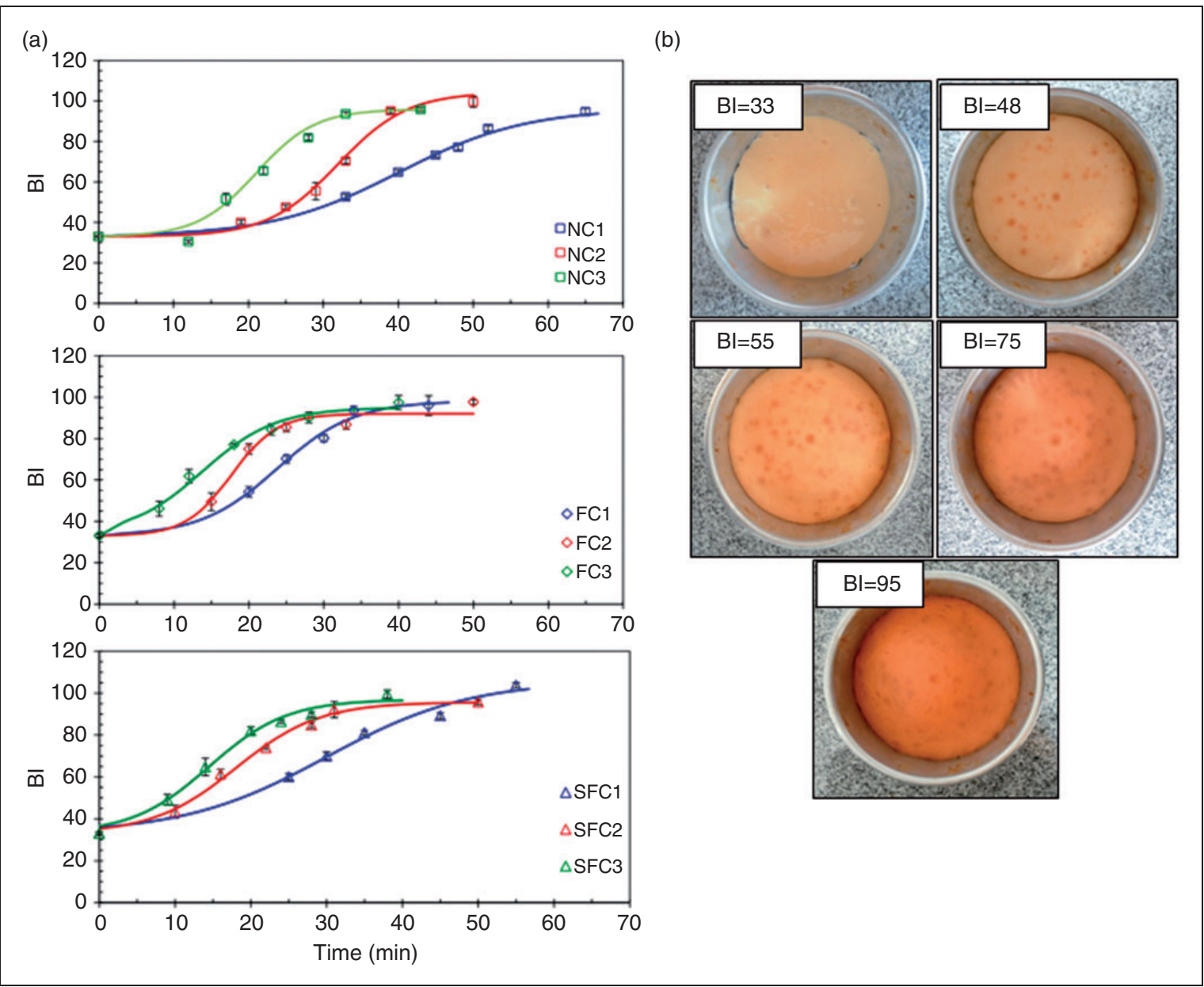

Figure 2. Surface colour evolution: (a) browning index along baking, experimental (symbols) and kinetic model (full lines) and (b) photographs showing a colour sequence under NC2 condition. 
et al., 2014b). Beginning from its initial value, $B I=33$, it shows first an induction period, the length of which depends on oven condition, and then starts increasing gradually up to a stabilization value where crust colour presents a value in the range of 100-110. Similar levels of BI were calculated from the CIELab values provided by other authors who studied different aspects of cake baking process (Baik et al., 2000; Psimouli and Oreopoulou, 2013). In order to predict BI evolution, different fitting equations were tested: zero order, first order, parabolic, Weibull, logistic and dose-response. The fitting procedure was performed with Origin Pro 8, the dose-response function (equation (3)) being the best model to describe the experimental curves $\left(R^{2}>0.94\right)$

$$
\mathrm{BI}=\mathrm{BI}_{\mathrm{o}}+\frac{\left(\mathrm{BI}_{\max }-\mathrm{BI}_{\mathrm{o}}\right)}{1+10^{\left(\mathrm{t}_{12}-\mathrm{t}\right) \mathrm{p}}}
$$

where $\mathrm{BI}$ is the browning index measured at time $\mathrm{t} ; \mathrm{BI}_{\mathrm{o}}$ is the initial browning index of the batter (equal to 33.02); $\mathrm{BI}_{\max }$ is the maximum value; $\mathrm{p}$ is a kinetic constant $\left(\min ^{-1}\right)$ and $t_{1 / 2}(\min )$ is the time at which $\mathrm{BI}$ value is the average between $\mathrm{BI}_{\mathrm{o}}$ and $\mathrm{BI}_{\max }$. The kinetic parameters $p, t_{1 / 2}$ and $\mathrm{BI}_{\max }$ and the coefficient of determination $\mathrm{R}^{2}$ are reported in Table 2 . As can be seen, both $\mathrm{p}$ and $\mathrm{BI}_{\max }$ are not different in a statistical sense, instead $t_{1 / 2}$ follows the same trend as the baking time respect to $\mathrm{T}_{\text {eff: }}$ an exponential decrease with an increase of $\mathrm{T}_{\text {eff }}$, two groups of data could be distinguished (NC and FC/SFC modes). (Table 1).

Water content. Taking into account that water content is one of the principal characteristics that defines the crust region and differentiates it from the crumb, it was monitored during sponge cake baking in the two zones. Figure 3(a) shows the results obtained under the NC1 condition. It was observed that the crumb maintains the initial batter water content $(36 \%$, w.b.); on the other hand the crust presented a noticeable dehydration during the process, with its final water content value around $10 \%$. Lostie et al. (2002a, 2002b) and SakinYilmazer et al. (2012) informed similar trends in cake crust and crumb water contents. At last, this parameter was measured in both zones at the end of baking for all conditions tested in this work; the results are presented in Table 2.

The analysis of these data suggests that crumb water content is not influenced by the baking condition, with its value between $34 \%$ and $35 \%$, slightly lower than the initial one. On the other hand, it is confirmed that the crust suffers an important dehydration in all the tested baking conditions. Besides, dehydration is less severe when steam is added to the baking chamber (SFC), and in NC and FC modes, a more drastic surface dehydration occurs when the oven temperature increases.
Crust/crumb ratio and crust thickness. Table 2 also details the physical characteristics measured in sponge cakes baked at $\mathrm{t}_{\text {min }}$ : crust/crumb ratio, crust thickness and related to the crumb porosity, density and firmness.

The average crust/crumb ratio is $0.06 \pm 0.01$ (g crust $/ \mathrm{g}$ crumb). The dispersion of these values is due to the methodology used to manually remove the crust from the cake. The average crust thickness, measured with a more precise technique, ultrasound (Figure 3(b)), is $1.00 \pm 0.04 \mathrm{~mm}$ with the exception of the $\mathrm{NC} 1$ condition. The minimum baking time at this baking condition is the largest one (Table 1), which can explain the development of a thicker crust.

Both precedent values confirm that the sponge cakes have a thin crust, the crumb being the major zone of the final product. Besides, baking is a heat transfer process that causes a combination of chemical and physical reactions comprising the formation of the spongy structure, typical of this kind of product (Hesso et al., 2015; Sakin et al., 2007). As a consequence, in relation to the product structure, the influence of the baking conditions (convection mode, oven temperature) on the crumb's structural properties must be analysed.

Crumb structure. Crumb porosity was determined using an image analysis technique; some images are shown in Figure 3(c). A similar methodology was used by Pérez-Nieto et al. (2010) to analyse the structural changes during bread baking. It was observed that for all the convection modes tested in this work, the sponge cake crumb presents a uniform porous distribution, without the existence of the channels or macro pores that are observed in other sweet baked products (Ureta et al., 2014a). However, from the results detailed in Table 2, a significant influence of the convection mode or the oven temperature is observed. NC baking and low oven temperature (NC1 and $\mathrm{NC2}$ ) provide high crumb porosity $\left(7.9 \pm 0.2\right.$ cell $\mathrm{cm}^{-2}$, average value). On the other hand, cakes obtained with forced convection (FC and SFC) had similar and smaller porosity values (6.6 \pm 0.6 cell $\mathrm{cm}^{-2}$, averaged value)

Table 2 also details crumb density values. No significant differences were found between different baking conditions; the average crumb density value was $404 \pm 15 \mathrm{~kg} \mathrm{~m}^{-3}$. Similar results were reported by other authors. In this sense, Gómez et al. (2007), who compared cakes formulated with different origins and chemical structure of hydrocolloids, informed a crumb density in the range of $380-450 \mathrm{~kg} \mathrm{~m}^{-3}$ including the control sample (without hydrocolloid). Kocer et al. (2007) studied the effect of using polydextrose as a sugar and fat replacer analysing several quality attributes; they informed crumb density values in a range of $290-380 \mathrm{~kg} \mathrm{~m}^{-3}$. 


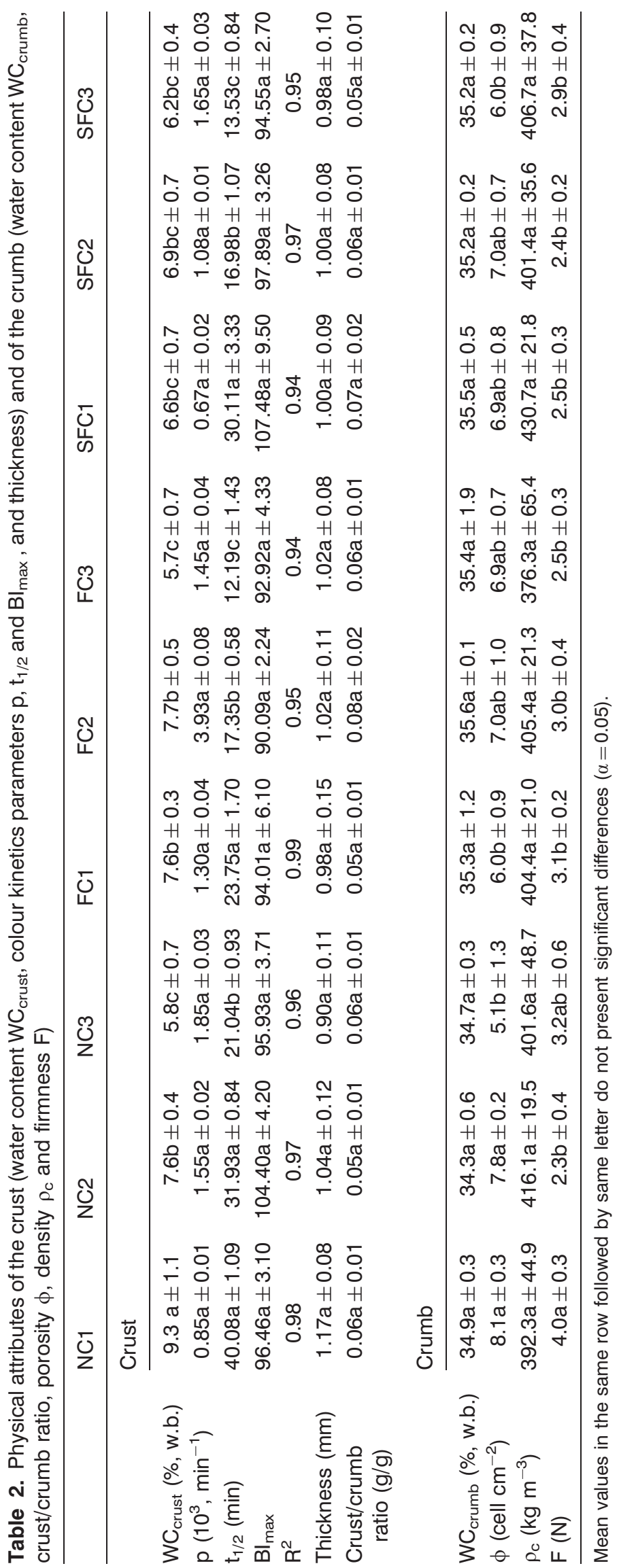


Ureta et al.

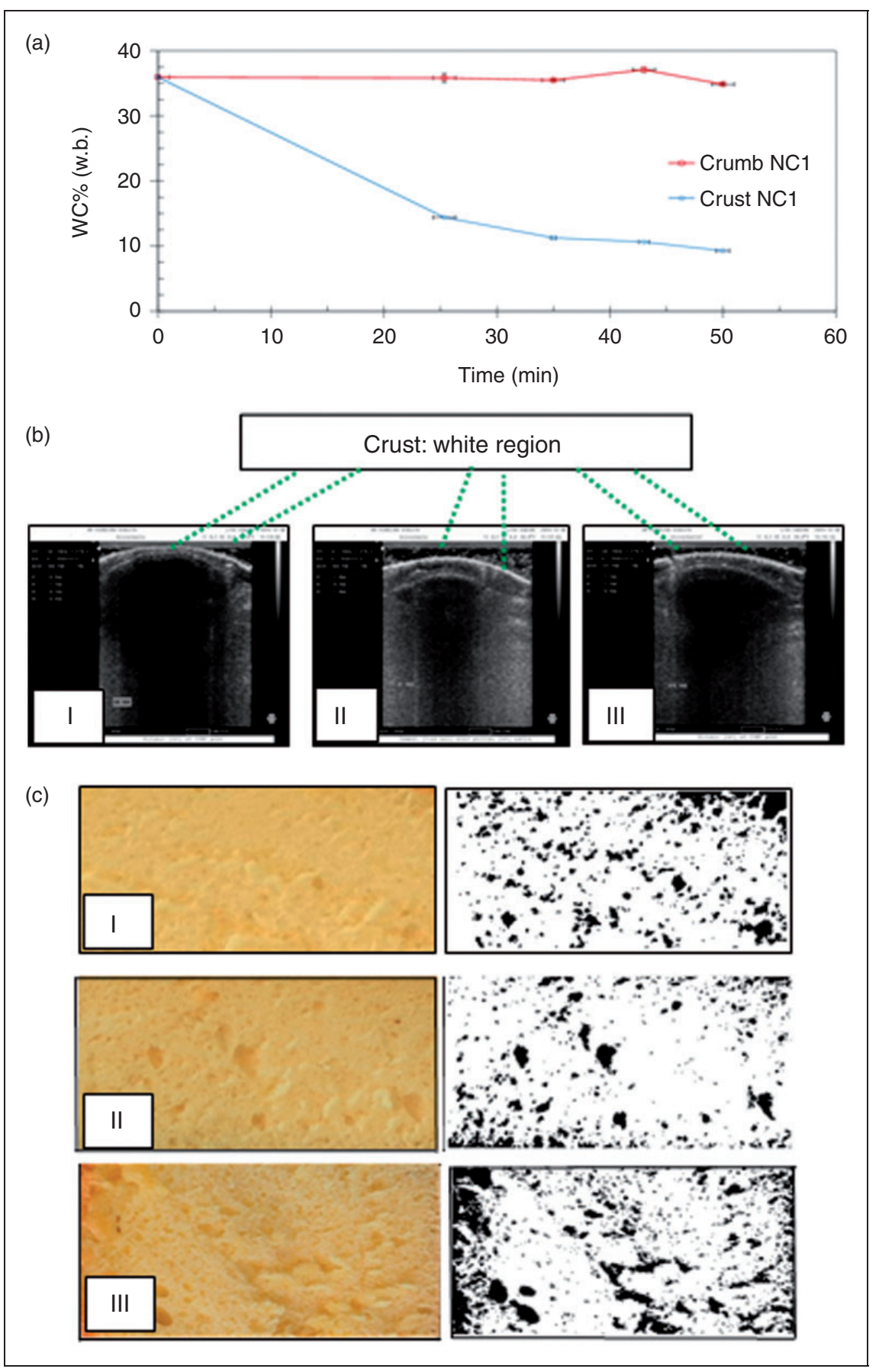

Figure 3. Crust and crumb measurements: (a) water content evolution (NC1 condition); (b) images obtained with the ecograph and (c) crumb images (RGB and binary); I, II and III correspond to NC1, FC1 and SFC1 modes, respectively.

To complete crumb characterization, crumb firmness (Table 2) was determined through a compression test. For all the baking conditions, cake firmness values were in the range of 2.3-4.0 N. Similar firmness values were reported by Meziani et al. (2012) who studied the influence of freezing conditions and the amount of leavening agents in the final quality (physical and sensory) of a bakery product (Kougelhopf, a typical cake from Germany, Alsace, Austria and Switzerland).

For the baking modes without steam injection (NC and FC), a significant decrease in crumb firmness, when the oven temperature increases, was observed. On the other hand, a humid ambient during baking (SFC) encouraged a less firm crumb, independently of oven temperature. 


\section{CONCLUSIONS}

In this work, the influence of baking conditions (oven temperature, convection mode, steam injection and baking time) on the quality attributes of sponge cake (defined by means of instrumental characterization and sensory analysis) was analysed.

Browning kinetics was modelled by means of a BI. A dose-response model accurately adjusts to experimental values of BI vs. time; kinetics parameters of colour change strongly depend on baking condition.

Two zones are distinguished in the sponge cake, crust and crumb. During baking, water content in the crumb remains almost constant while considerable dehydration occurs in the crust. No significant differences among baking conditions in crust thickness or crumb structure were measured by the different instrumental techniques, the crust resulting really thin (around $1 \mathrm{~mm}$ ) and the crumb being light and aerated.

\section{HIGHLIGHTS}

- The influence of baking conditions on the development of cake quality was analysed.

- Baking conditions strongly influences the development of cake surface colour.

- No significant differences were measured in crust thickness or crumb structure.

- The crust resulted really thin (around $1 \mathrm{~mm}$ ) and the crumb, light and aerated.

\section{DECLARATION OF CONFLICTING INTERESTS}

The author(s) declared no potential conflicts of interest with respect to the research, authorship, and/or publication of this article.

\section{FUNDING}

The author(s) disclosed receipt of the following financial support for the research, authorship, and/or publication of this article: Authors acknowledge CONICET (PIP GI 0180 and PIP IU 0259), MINCYT (ANPCyT PICT 2013-1637), and UNLP (11I183) from Argentina for their financial support.

\section{REFERENCES}

Ahrné L, Andersson C, Floberg P, Rosén J and Lingnert H. (2007). Effect of crust temperature and water content on acrylamide formation during baking of white bread: Steam and falling temperature baking. LWT-Food Science and Technology 40: 1708-1715.

Baik OD, Marcotte M and Castaigne F. (2000). Cake baking in tunnel type multi-zone industrial ovens. Part I. Characterization of baking conditions. Food Research International 33: 587-598.
Chhanwal N, Ezhilarasi PN, Indrani D and Anandharamakrishnan C. (2015). Influence of electrical and hybrid heating on bread quality during baking. Journal of Food Science and Technology 52: 4467-4474.

Fehaili S, Courel M, Rega B and Giampaoli P. (2010). An instrumented oven for the monitoring of thermal reactions during the baking of sponge cake. Journal of Food Engineering 101: 253-263.

Gómez M, Ronda F, Caballero PA, Blanco CA and Rosell CM. (2007). Functionality of different hydrocolloids on the quality and shelf-life of yellow layer cakes. Food Hydrocoloids 21: 167-173.

Hesso N, Garnier C, Loisel C, Chevallier S, Bouchet B and Le-Bail A. (2015). Formulation effect study on batter and cake microstructure: Correlation with rheology and texture. Food Structure 5: 31-41.

Kocer D, Hicsasmaz Z, Bayindirli A and Katnas S. (2007). Bubble and pore formation of the high-ratio cake formulation with polydextrose as a sugar- and fat-replacer. Journal of Food Engineering 78: 953-964.

Kossoff G. (2000). Basic physics and imaging characteristics of ultrasound. World Journal of Surgery 24: 134-142.

Le-Bail A, Dessev T, Leray D, Lucas T, Mariani S, Mottollese G, et al. (2011). Influence of the amount of steaming during baking on the kinetic of heating and on selected quality attributes of bread. Journal of Food Engineering 105: 379-385.

Lostie M, Peczalski R, Andrieu J and Laurent M. (2002a). Study of sponge cake batter baking process. Part I: Experimental data. Journal of Food Engineering 51: 131-137.

Lostie M, Peczalski R, Andrieu J and Laurent M. (2002b). Study of sponge cake batter baking process. Part II: Modeling and parameter estimation. Journal of Food Engineering 55: 349-347.

Meziani S, Kaci M, Jacquot M, Jasniewski J, Ribotta P, Muller JM, et al. (2012). Effect of freezing treatments and yeast amount on sensory and physical properties of sweet bakery products. Journal of Food Engineering 111: 336-342.

Pérez-Nieto A, Chanona-Pérez J, Farrera-Rebollo RR, Gutiérrez-López GF, Alamilla-Beltrán L and CalderónDomínguez G. (2010). Image analysis of structural changes in dough during baking. LWT - Food Science and Technology 43: 535-543.

Psimouli V and Oreopoulou V. (2013). The effect of fat replacers on batter and cake properties. Journal of Food Science 78(10): 1495-1502.

Sakin M, Kaymak-Ertekin F and Ilicali C. (2007). Simultaneous heat and mass transfer simulation applied to convective oven cup cake baking. Journal of Food Engineering 83: 463-474.

Sakin-Yilmazer M, Kaymak-Ertekin F and Ilicali C. (2012). Modeling of simultaneous heat and mass transfer during convective oven ring cake baking. Journal of Food Engineering 111: 289-298.

Sakin-Yilmazer M, Kemerli T, Isleroglu H, Ozdestan O, Guven G, Uren A, et al. (2013). Baking kinetics of muffins in convection and steam assisted hybrid ovens. Journal of Food Engineering 119: 483-489. 
Sani NA, Taip FS, Kamal SM and Aziz N. (2014). Effects of temperature and airflow on volume development during baking and its influence on quality of cake. Journal of Engineering Science and Technology 9(3): 303-313.

Shahapuzi NS, Taip FS, Aziz NA and Ahmedov A. (2015). Effect of oven temperature profile and different baking conditions on final cake quality. International Journal of Food Science and Technology 50: 723-729.

Sumnu G, Sahin S and Sevimli M. (2005). Microwave, infrared and infrared-microwave combination baking of cakes. Journal of Food Engineering 71: 150-155.

Turabi E, Sumnu G and Sahin S. (2008). Optimization of baking of rice cakes in infrared-microwave combination oven by response surface methodology. Food Bioprocess Technology 1: 64-73.
Ureta MM, Olivera DF and Salvadori VO. (2014a). Quality attributes of muffins: Effect of baking operative conditions. Food and Bioprocess Technology 7: 463-470.

Ureta MM, Olivera DF and Salvadori VO. (2014b). Baking of muffins: Kinetics of crust color development and optimal baking time. Food and Bioprocess Technology 7: 3208-3216.

Ureta MM, Olivera DF and Salvadori VO. (2016). Baking of sponge cake: Experimental characterization and mathematical modelling. Food and Bioprocess Technology 9: 664-674.

Vignali G and Volpi A. (2013). Analysis and evaluation of cooking parameters for sweet bakery products. Advance Journal of Food Science and Technology 5: 843-854. 